\title{
Analysis of Chinese Patent on Electric Vehicles
}

\author{
Yurong Huang ${ }^{1,}$, Yuanyuan Hou ${ }^{1}$, Huina Zhang ${ }^{1}$, Tong Liu², \\ Chensheng $\mathrm{Wu}^{1}$ \\ ${ }^{1}$ Beijing Institute of Science and Technology Information, Beijing, China, 100044 \\ ${ }^{2}$ Beijing Computing Center, Beijing, China, 100094 \\ ahyrta@126.com
}

\begin{abstract}
Keywords: Battery Electric Vehicle(BEV), Hybrid Electric Vehicle(HEV), Fuel Cell Electric Vehicle (FCEV), Patent Information

Abstract: As the global environment pollution and energy crisis intensified, electric vehicles has been becoming the R\&D hot technology all over the world for the two features of energy saving and environmental protection. Electric vehicles mainly includes Battery Electric Vehicle(BEV), Hybrid Electric Vehicle(HEV) and Fuel Cell Electric Vehicle (FCEV) three types. The article analyzes the patent situation, the patent application of other countries in China about BEV and HEV and FCEV respectively, in order to show the Chinese electric vehicle patent status.
\end{abstract}

\section{Introduction}

As the global environmental pollution and energy crisis is worsening, electric vehicle has attracted extensive attention all over the world, and it also has been getting great development. [1]For China, electric vehicle is the path towards the world automobile powerhouse and corner overtaking, and Chinese government has launched a number of policies continuously to promote the development of electric vehicle industry, and invest a lot of financial, human and material resources in the development of electric vehicle since 2010. [2] Now, the complete electric vehicle and parts industry pattern has formed nationwide, and the electric vehicle technology has been greatly improved. [3]

How about China's electric vehicle industry technology level? Who is the main patent application body? How is other countries patent layout in China? All the information is very important for the research and development strategy making and the technologies of vehicle companies. Patent is one of the main outcome forms of scientific research innovation, and contains abundant technical information, market information and legal information. [4]To conduct a comprehensive patent literature analysis can reveal electric vehicle patent application situation and the patent layout strategy of other countries in china , and other important competitive information, and also can help enterprises to improve their innovative ability and keep healthy development, and improve the overall competitiveness. [5] This paper analyzes the electric vehicle patent technology in China, and aims to provide patent intelligence support for the electric vehicle technology and product development of Chinese enterprises, and relevant departments to formulate strategy.

\section{Data Sources and Research Methods}

The patent data is retrieved by combining keywords and IPC on the Chinese Patent Database of patent data retrieval platform of State Intellectual Property Office of the P.R.C on October 22, 2015, and 36487 Battery Electric Vehicle(BEV) patents and 12410 Hybrid Electric Vehicle(HEV) patents and 5559 Fuel Cell Electric Vehicles (FCEV)patents were retrieved. The patents data are processed by using the data analyze tools of TDA, Thomson Innovation and Excel, and then analyze the patent data by using the patent statistics, patent map analysis method deeply.

All the patent data retrieved are public. Because the patent will spend 18 months to three years from application to publication, so the patent annual application number began to appear distortion in2013, and the patent data after 2013 is for reference only. 


\section{The Electric Vehicle Patent Application Status Analysis}

Electric Vehicle contains three types: Battery Electric Vehicle(BEV), Hybrid Electric Vehicle(HEV), Fuel Cell Electric Vehicles (FCEV), all the analysis in the paper will be revolves around the three types of electric vehicles.

2.1 The patent application trend analysis. The total number of electric vehicle patent application per year in China from 1988 to 2014 is shown in Fig.1. BEV patent started relatively early, the first patent an application appeared in 1988, then the number of patent increased year by year, steadily, and the number increased steadily year by year especially after 2000, and the number began to increase after 2009 rapidly, BEV technology has entered into the phase of rapid development. The development of HEV and FCEV started relatively late, the first patent of HEV appeared in 1994, the patent number is not more than 50 per year until 2004, the development is slow relatively, the number of HEV patent increased steadily year by year after 2004, HEV technology is still in the development stage. The first FCEV patent appeared in 1999, the patent application presents ascendant trend in addition to the number declining slightly in 2009, but overall, the number of patent is small relatively.

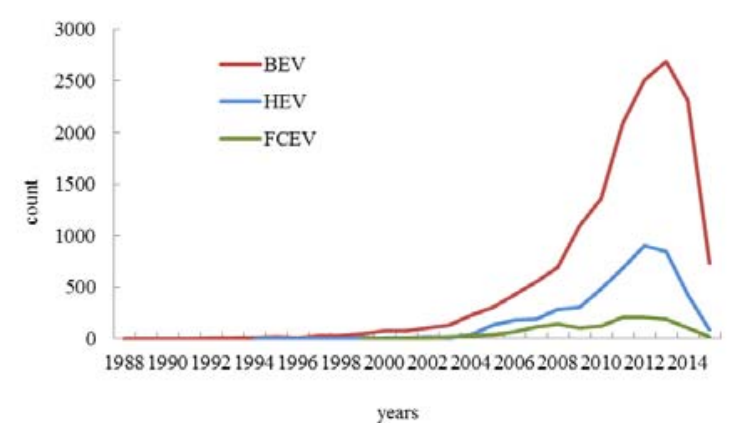

Fig.1 The number of electric vehicle patent application in China

\subsection{The Assignee Type Analysis}

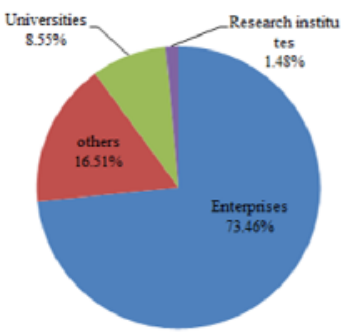

$\mathrm{BEV}$

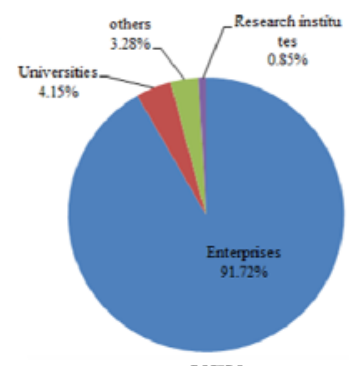

HEV

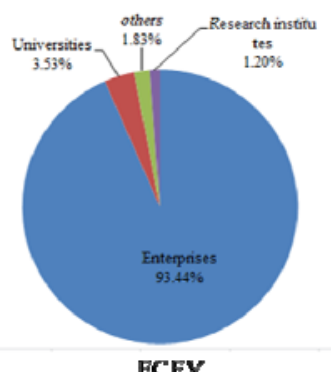

FCEV

Fig.2 The proportion of Assignee type of three electric vehicle types

The main body of technology research and development of three electric vehicle types is shown in Fig.2. The proportion of enterprise's patent is as high as $73.46 \%, 91.72 \%$ and $93.44 \%$ respectively, and the number of universities' patent are more than the research institutes' in BEV and HEV. It is worth noting that universities and research institutes doing pure research, the research direction are often industry technical bottlenecks basically, patents often represent the technical breakthrough direction. Compared with companies, universities and research institutes have sufficient talents and advanced research equipment, and innovation ability is more stronger, but research funds is lack relatively, and market sensitivity is poor. The demands for innovation of companies are strong, and they also have abundant R\&D budgets, and pay more attention to transforming technology into productivity, so companies, universities and research institutes should strengthen cooperation to make up for the shortcomings and achieve common development. 


\section{The Application Country and Regions of Electric Vehicle Patent}

\subsection{The BEV Patent Application}
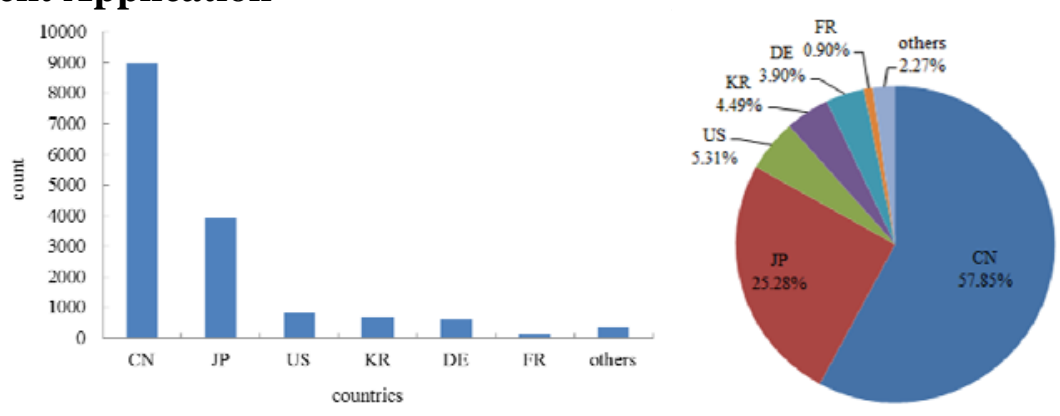

Fig.3 Application countries of BEV patent

The BEV patent application countries is shown in Fig.3. Japan applied for the most number of BEV Patents among foreign countries in China, followed by the United States, South Korea, Germany, France, they are all powerful countries in automobile industry. The proportion of BEV Patents our country apply for account for $57.85 \%$, it shows that many enterprises in our country are taking battery electric vehicle as the main direction of new energy vehicles, and pay more attention to the research and development of battery electric vehicles. This is also consistent with the hope to break through by battery electric vehicle overtaking around the curve, and among the ranks of the world's leading automotive powerhouse.

\subsection{The HEV Patent Application}
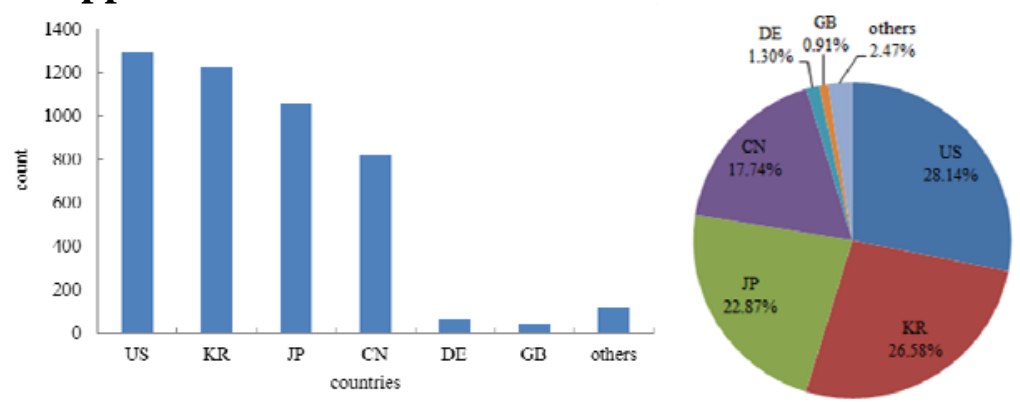

Fig.4 Application countries of HEV patent

The HEV patent application countries is shown in Fig.4.Because China's automobile companies are at a technological disadvantage in internal-combustion engines, and this hinder the research and development of HEV in our country, and the number of HEV patent of our country is low. It also shows that the gap between our country and the United States, South Korea, Japan is large. The United States, South Korea and Japan are all take great importance to Chinese HEV market.

\subsection{The FCEV Patent Application}
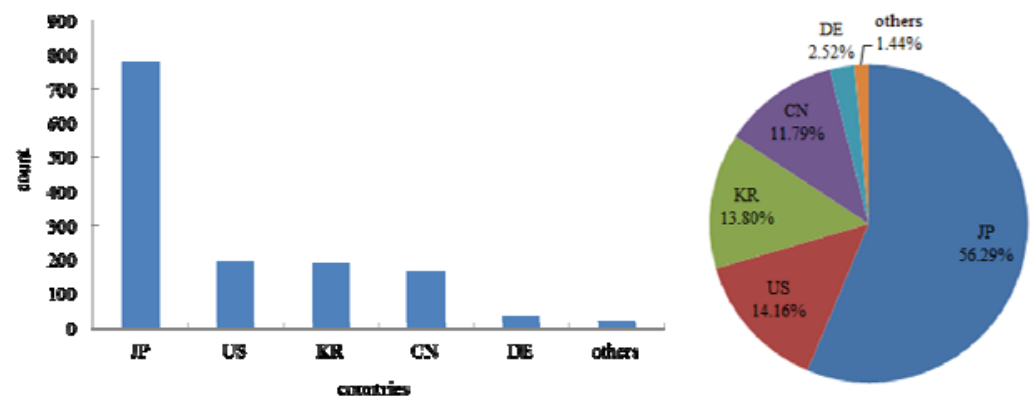

Fig.5 Application countries of FCEV patent

The FCEV patent application countries is shown in Fig.5. Japan applied for the largest number of FCEV Patent in China, and the proportion of Japan's FCEV patent is 56.29\%, followed by the United States(14.16\%), South Korea(13.80\%),while China's domestic patent application rank fourth, the proportion is only $11.79 \%$, the gap between our country and Japan is very large. 
FCEV is the ultimate development direction of new energy vehicles, the developed countries, such as Japan, the United States, South Korea still spend a lot of resources for research and development although the limitation of fuel cell technology bottleneck hampers its commercialization. Especially starting in 2004, three research and development of FCEV alliance was established between the world's major car manufacturers, and Toyota announced that it will realize volume production of FCEV, FCEV will be the most powerful competitor of BEV. In our country there is no other Corporations invest in the research of FCEV besides China FAW Group Corporation SAIC Motor Corporation Limited, so the gap between our country and developed countries is growing, government and enterprise should pay more attention to the research and development in China.

\section{Conclusions}

The paper analysis the electric vehicles patent application retrieved on Chinese Patent Database of SIPO, we can see Chinese electric vehicle patent application presents the following features:

(1) Electric vehicle patent application steadily increasing in China. The research and development of BEV technology started early, and the development is relatively mature, and it goes into rapid development period. The research and development of HEV and FCEV started late relatively, the development is slow, and the development of HEV is in development period, and the patent application of FCEV is still less.

(2)Enterprises are the main body of electric vehicle research and development, the proportion of the amount of patent accounted for the total amount is very high. Because the universities and R\&D institutions attach great importance to the research of industrial technology bottleneck, but pay less attention to utility, while enterprises pay attention to the industrialization of scientific and technological achievements.

(3)Japan, the United States and South Korea apply a large number of electric vehicles patents in our country. BEV domestic patent application proportion is more than 50\%, HEV and FCEV domestic patent application is obvious at the disadvantage, the gaps with the United States, South Korea, Japan are great, the research and development gap between our country and developed countries continues to increase in the field of FCEV especially, and government and enterprises should pay more attention on the research and development of FCEV.

\section{Acknowledgements}

This work was funded by the Beijing Municipal Financial Research Program (No.PXM2016-178214-000006) and the National Natural Science Foundation of China (71303023).

\section{References}

[1] Hailong Jiang, Ruibin Wei: submitted to Journal of Modern Information(2013),In Chinese.

[2] Rong Wang,Zhanglin Wang, Shouxia Wang: submitted to Journal of Auto Engineer(2015), In Chinese.

[3] Lifeng Yang, Kaihua Chen: submitted to Journal of Science Research Management(2013), In Chinese.

[4] Lei Cao: submitted to Journal of Science and Technology Management Research(2005), In Chinese.

[5] Qingmin Wang: submitted to Journal of Modern Information(2007), In Chinese. 